\title{
Bottom-up and inside-out: using participatory methodology to measure the social impact of a radio engagement project with young people of refugee experience
}

\section{Heather Anderson and Shepard Masocha}

\section{Abstract}

Given the current context of resource constraints and austerity cuts, there is an imperative to evidence the social impact of community radio in order to safeguard the sector's continued existence. The divergent and complex nature of the community broadcasting sector complicates the matter of social impact measurement, as does the general lack of consensus within academic debates on how best to measure, record and demonstrate its long-term effects (Jallov 2005). This article focuses specifically on the use of participatory monitoring and evaluation processes as a way of determining social impact. It provides insight into how a bottom-up and inside-out approach, embedded within a participatory action research methodology, can be useful for assessing the social impact of community radio projects. It focuses on a radio series produced by young people from refugee backgrounds living in Adelaide, South Australia, part of a pilot research project to investigate how media engagement can positively contribute to resettlement experiences.

\section{Introduction}

Australia has one of the most well established community broadcasting sectors in the world, first licensed in 1972. It is specifically legislated to require public participation and represents the "Third Sector" of broadcasting, which exists alongside commercial operations and government-funded stations. Radio dominates the sector with over 360 radio station licensees and an additional 80 community television licensees across the country (CBF 2015). Australian community radio represents a variety of geographic communities with an audience of over nine million people, listening in towns and cities across the country with the largest proportion located in regional areas (41\%), a further 25\% in rural areas and 34\% across metropolitan and suburban locations (CBAA 2015). Stations vary greatly depending on the community to which they broadcast, from radical and political to religious and educational. Radio stations serve the many needs and interests or specific communities of interest - 
including youth, senior citizens, arts, fine/specialist music, educational, Australian music, sport and other specialist interests, as well as providing specific services for ethnic, Indigenous, religious communities and people with print disabilities.

In 2002, the Culture, Commitment, Community study into the Australian community radio sector reported that although there was a sharp growth in the number of stations since 1987 this had not been matched by a concomitant increase in available funding. Instead the core funding guaranteed to the sector on an annual basis from the Federal government has actually decreased over time. The sector has also been a target of current austerity measures being implemented by the government. In May 2014, the National Commission of Audit (established by the new Coalition Government to look for savings to government expenditure) recommended the abolishment of the Community Broadcasting Program, through which community radio stations receive Commonwealth funding. The National Commission of Audit provided the following rationale for cutting all government funding to the community broadcasting sector:

The Commonwealth Government already provides over $\$ 1$ billion per annum to the operation of the public broadcasters [SBS and $\mathrm{ABC}$ ]. There is a limited rationale for the Commonwealth to also subsidise community radio services. Continued government funding of this area does not meet the Report's principles of good governance (National Commission of Audit 2014, p.141).

While this recommendation was not implemented in the 2014-15 budget, following a strong campaign against the proposed cuts, it did result in a four-year freezing of the indexation for the Community Broadcasting Program, which according to peak body, the Community Broadcasting Association of Australia (CBAA 2015) constituted a cut of just over $\$ 3$ million over that four years. According to the CBAA's general manager more than 100 stations would be faced with closure if government funding was to cease (Bisset in Gough 2014). Therefore, given the current context of resource constraints and austerity cuts, there is an imperative to evidence the social impact of community radio in order to safeguard the sector's continued existence. As Order (2012, p.62) points out, if the value of community broadcasting could be identified then it should be easier for the sector to attract and justify funding. 
Social impact is defined as "the societal and environmental change created by activities and investments" and includes unintended and intended, positive and negative, and short and long term effects (Grieco 2015, p.44). Through their research into measuring the impact of Video for Social Change, Notley, Lowenthal \& Gregory (2015, p.13) define the action of assessing impact as documenting "what has changed" along with those elements that have contributed to that change. As Order (2012, p.62) notes, the community broadcasting sector itself is a "divergent and contested theoretical terrain" which further complicates the matter of developing a clear understanding of what "value" looks like within the sector (Order 2012, p.62). As such, there is a general lack of consensus within academic debates on how best to measure, record and demonstrate its long-term effects (Jallov 2005). Whiteman (2004) argues that traditional modes of assessing the impact of documentaries (such as box office takings and audience numbers) are not appropriate when considering the impact of social movement media. Instead, he suggests that the film is considered "as one point of the continuum" with a life both before and after broadcast. This is in line with Notley, Lowenthal \& Gregory's (2015, p.13) findings that an impact framework for community media needs to consider the entire initiative, using an approach that considers the entire "process and seeks out points of impact along that pathway, to assist practitioners understand what is both working, and not working".

There is a paucity of research that evaluates the social impact of community radio. One exception to this is a study in 2007 by the World Association of Community Broadcasters (AMARC) which published its findings from a long-range participatory action research project that involved 927 community radio stakeholders from 96 countries to explore the barriers that limit the potential positive impact of community radio and ways to increase its effectiveness. AMARC (2007) pointed to three necessities; a need for appropriate tools and indicators to evaluate the social impact of community radio that go beyond information dissemination indicators; a need for further research on how to increase the effectiveness of community radio; and a need to embed participatory monitoring and evaluation across the community radio network (Solervicens in AMARC 2007). A main recommendation of the research was to more strongly develop the use of participatory monitoring and evaluation processes. AMARC (2007, p.8) found that the measurement of community radio social impact should be people-centred with key indicators being related to "voice, empowerment and local ownership of communication processes". This article focuses specifically on the use of participatory monitoring and evaluation processes as a way of determining social impact. It 
applies and builds on this framework to provide an insight into how a bottom-up and insideout approach can be useful for assessing the social impact of community radio. It focuses on a radio series produced by young people from refugee backgrounds living in Adelaide, South Australia, part of a pilot research project to investigate how media engagement can positively contribute to resettlement experiences.

\section{$\underline{\text { Measuring social impact }}$}

Understanding social impact assessment allows organisations to apply it in pro-active and goal-oriented ways and "drive their actions to result in advantages and development for communities" (Grieco 2015, p.46). However, social impacts can be hard to measure due to their qualitative nature making it a challenge to define a clear approach (Mass and Liket 2011). There are both short term and long term social impacts that need to be accounted for and it is difficult to attribute specific impacts to specific actions. In addition, issues such as time, resources and other (often more immediate) commitments act as obstacles to undertaking impact measurement. These challenges are echoed through much of the literature that looks at social impact measurement (see for example Barraket \& Yousefpour 2013; Bloch 2012; Zappala \& Lyons 2009; Jallov 2005). While there are obvious benefits to a formalised collection of social impact measurement data, the difficulties associated need to be recognised at a policy level if they are to be sufficiently addressed (Zappala \& Lyons 2009).

Kramer, Parkhurs and Vaidyanathan (2009) identified a number of shared measurement platforms for monitoring social impact of not-for-profits and social enterprises, however, these tools tend to be quantitative in nature and less likely to suit the needs of community broadcasting. Indeed this was one of the findings of Notley, Lowenthal \& Gregory's (2015) study into measuring the impact of Video for Change. The authors suggest that alternative ways of recognising impact are neglected "in a rush to declare success by counting online views, hits, tweets, comments and clicks" (Notley, Lowenthal \& Gregory 2015, p.11). As a result, what is actually measurable becomes over-emphasised. The AMARC (2007) study into community radio social impact also found that quantity indicators, such as number of hours of programming dedicated to a specific topic or measurement of audience, tell only part of the story - yet, in the absence of more qualitative assessments, these quantitative measures tend to be required by funding bodies. While quantitative data should not be discounted completely, Notley, Lowenthal \& Gregory (2015) suggest we need to find operational ways in which to collect "thick data" (Wang 2013), which focuses on telling stories and ensures 
that quantitative data is not disassociated from its contexts. This article foregrounds the importance of 'thick data' in the development of a nuanced understanding of the social impact of community radio.

Jallov (2005) identified three levels of impact that need to be addressed within an assessment of community radio. One is the level of impact on the community more broadly to "ensure that the community radio station in the longer term actually manages to create some of the desired basic social change in the community" (Jallov 2005, p.30). Then there is the level of the radio station as an organisation. This can be measured through periodic self-assessments that aim to map how the station is evolving in regards to funding, human resources (including participation) and management. Finally, and most relevant to this paper, is impact at the level of the radio programs themselves, to ensure they are responding to the interests and needs of the communities. It is important to recognise these three separate levels of assessment within the broadcasting sector when identifying the key outcomes that community broadcasting sets out to achieve. It is this third "micro" level of impact that shall be discussed in the case study below.

\section{The case study}

Powerhouse Radio Show (P-HRS) is nine-episode radio series, produced by young people from refugee backgrounds, for UniCast, an internet radio station operated out of the School of Communication, International Studies and Languages, at the University of South Australia (UniSA). The radio station is licensed as an Online Mini Licence - Live Webcasting - Tier C, through the Australasian Performing Rights Association Ltd. While it is not a community radio station, it operates as a community media outlet for UniSA students, and for the first time through P-HRS, engages the wider local public.

P-HRS was developed out of a pilot participatory action research project that involved young people from refugee backgrounds in media and radio production workshops to investigate solutions to the challenges of their resettlement. The pilot is being conducted to explore the potential for replication throughout the community broadcasting sector, and acknowledges there are specific settlement concerns relating to practical support, community development, trauma recovery and other complex needs of refugees (NEMBC 2011). The project targeted young people of refugee background aged 18 to 25 years. There were 9 participants recruited through a number of community organisations including the Australian Refugee Association (ARA), Multicultural Communities Council of South Australia (MCCSA), Welcome to 
Australia SA and Multicultural Youth South Australia (MYSA) as well as the student clubs, UniSA African Society and UniSA Afghan Students Association.

\section{Methodology}

Participatory action research involves testing ideas in practice as a means of improving social, economic or environmental conditions and increasing knowledge. It involves close collaboration between practitioners and researchers and is particularly valuable as a means of exploring new media initiatives (Hearn et al 2009). The research project is currently still underway and data is being gathered through a number of distinct approaches including:

- Ethnographic participant observations and reflection notes taken during and after the workshops

- Individual semi-structured interviews with participants to be conducted towards the end of the research project.

- Content analysis of the media broadcast as a result of the workshops

- Audio recordings produced during the training project not intended for broadcast

In essence, these data collection methods focused on collecting what Wang (2013) has coined 'thick data', which provides the story that humanises quantitative data. The concept of thick data stems as a response to the importance that tends to be attached to 'big data.' Big data is quantitative information that is produced through analysis of large data sets. Although large quantities of information can be generated through this process, more is needed to reveal and/or bridge knowledge gaps, and this can be provided through thick data. Thick data, produced within the realm of ethnography, provides context and connection and counteracts the notion that qualitative data is "small data".

In relation to developing a participatory monitoring and evaluation process by which to measure the social impact of the pilot, the last data collection method mentioned above is most relevant. In the third workshop, participants learnt to use recording equipment (portable H1 Zoom Recorders) by interviewing each other about the ideas they had for the radio show and how the success of the project could be measured. Paying attention to microphone technique as part of their training exercise, the participants based their discussions on the following questions:

- What are you hoping to get out of your involvement in this radio project? 
- How do you think we should measure the success of this project and what do you think success would look like?

- How would this success feel like to you?

- What do you think needs to happen for you to say you were happy with the project?

These questions were designed to ensure that the young people actively participated in evaluating the project. This methodology is in line with research conducted by Long et al (2002) who consulted with case study project team members to consider what outcomes they were aiming to achieve, and identify appropriate indicators of performance linked to these outcomes.

These interviews were transcribed and analysed using discourse analysis (Potter and Wetherell 1987; Wetherell 2015) in order to gain an understanding of the ways in which participants defined success and sought to measure the success or otherwise of their involvement in the project. This approach enabled a bottom-up and inside-out understanding of social impact. It recognises that participants are immersed in the daily life of the community and its issues. As such this approach validates the expertise of the participants' expertise by involving them in the evaluation process.

To make sense of the collected data, the study draws on poststructuralism which recognises the world as discursively constructed and lends itself to an understanding of the participants' subjective definitions of social impact. Patton (2003 p.5) warns that "performance is not some underlying attribute that exists and can be known independently of the people centrally involved" but rather "performance is what those people more or less agree, implicitly or explicitly, to be performance, what they have in mind when they use the term". The data analysis identified a number of the interpretative repertoires that were used by participants to articulate notions of success. Interpretative repertoires are "recurrently used terms for characterizing and evaluating actions, events and other phenomena" (Potter and Wetherell, 1987 p.149). Interpretative repertoires do not just constitute particular versions of the world (Potter and Wetherell 1987) but are also performative as they result in the construction of specific identities for the speakers themselves (Every and Augoustinos, 2007). The interpretative repertoires were identified through closely reading and re-reading the interview data number of times until as Edley (2001: , p.198-199) suggests 
... one begins to feel as though you've heard it all before. People seem to be taking similar lines or making the arguments as others previously interviewed ... Gradually one begins to recognise patterns across different people's talk, particular images, metaphors and figures of speech.

It is recognised that the participants' discussions were based around notions of 'success' rather than 'impact', as the term was a more familiar one for them to consider. While the two terms are different, there is sufficient comparison between the two for the data to be meaningfully applied to social impact measurement. Larkin (2013) refers to three types of data that might be used to measure the success of a not-for-profit as inputs, outputs and outcomes, which can equally be applied to measure social impact. In fact, establishing indicators or measurements of success is considered an important step in the process of social impact measurement (Productivity Commission 2010, Maughan 2012, Zappala \& Lyons 2009).

\section{$\underline{\text { Results and Discussion }}$}

Barraket (2005, p.14) argues that it is difficult to measure social impact "without measuring the effects of those initiatives on people over time". The findings provide important insights into the different dimensions of social impact from the perspective of the participants. The analysis of the participants' narratives revealed the following interpretative repertoires which are analysed in turn:

1. Constructing success as participation

2. Constructing success as a (collaborative and ongoing) process

3. Constructing success as tangible outcomes

4. Constructing success as making a difference

\section{Constructing success as participation}

Participants framed success primarily in terms of their participation in the project rather than specific outcomes that could be achieved at the end of the project. For instance, one participant noted how being involved in project activities, that were outside the realm of the young people's daily life-experiences, was in itself a marker of success. She stated:

I think it is a success already to have people here, to have people put up their hand and to be involved, to be able to do something that is outside their field. So that is a success for me. That's what I see as success... I like the idea of exploring 
things, in doing something new. Once you get involved in it you are already successful. Success does not mean the finishing.

Closely linked to this, the participants draw attention to the affective dimensions of success. Success is constructed in terms of the emotions that are evoked by being involved in the project. Participants spoke of success in terms of 'good feelings' emanating from their participation in the project. One participant observed that:

... if everyone is happy with what they are doing and how we are going, then that's success .. I have so far seen a lot of happy faces around here.

Another participant deploys a similar register of affective terms to construct success:

... there are things you want to do in this project and at the end you see how it looks ... everyone has a different way of thinking but in my perspective if I am happy at the end of this project then I will say I have achieved good success of it.

Another participant spoke of success of the project being measured in terms of the opportunities it afforded to the young people to "... [listen] to our own work and on the radio, accepting ... accepting that it's good ... and I have done this, and I'm proud of myself'. The interpretative repertoire of constructing success as participation resonates with Order's (2013, p.396) findings that "the value of community radio lies significantly in the personal benefits or satisfaction derived from participation in community radio"

\section{Constructing success as a (collaborative and ongoing) process}

The participants framed success as embedded in the whole life of the project initiative rather than an end product. This perspective resonates with Notley et al's (2015) argument for the need to look for 'points of impact' across the life of the project. Although these interviews were undertaken in the initial stages of the research project, one participant reported that:

It's already a good feeling for me because I'm in a very diverse setting and there is a lot of knowledge that is going to be shared. So, for me what success is going to look like, it's already started for me, looking good for me at the moment.

The participants identified the opportunity to exchange ideas and work collaboratively with others in the group as a marker of the success of their involvement in the project. One participant saw success as being able to "to come up with ideas for the radio show and be able 
to use all the ideas that [the researchers] have brought us and the skills they taught us as well as considering the ideas of the team members to be able to make a successful broadcast". These sentiments of success as a product of team work is clearly articulated in the following extract:

... [success] can be measured by the dedication of the participants. I think it will be measured by how much effort we put into it and I think the success will be measured by what will come out of those things we want to discuss, those places and stuff we want to touch, those voices we want to hear, those people we want to talk to. That's where I guess the measurement lies. It will be measured by those qualities of things we will produce as well.

Thus, success was located in the opportunities that the project offered participants to "work together and be active in our participation and get out of the box" and being "able to create something by ourselves". The participants were clear that the whole group should collectively share success. This notion of collective ownership of the success story was conveyed clearly by one participant who stated that success should "feel like a great achievement, not only to myself, but to the group".

\section{Constructing success as tangible outcomes}

The need to produce tangible outcomes was a recurring feature across the participants' narratives. For instance, one participant felt that the success of the project was to be "measured by the outcome" with another similarly saying he could "measure this project according to the outcome", with 'outcome' in both cases being a reference to the actual broadcasted programs. It is important to highlight here that although there was a particular focus on outcomes within the participants' narratives, it was also clear across the narratives that the participants themselves determined such outcomes. For example, one participant argued that, "If we can come up with the ideas we want to pursue and set the target - what we are really looking for ... [and] the time frame ... we can measure our success". The idea of participants having the power to decide on the outcomes and how to measure them as opposed to these being determined in a top-down manner is clearly conveyed in the following extract:

I think success is measured by the outcome ... And we also measure the success of this project through our own standards, like the level we are operating, if we ... 
(are) ... satisfied with our standards, the levels that we are working at, I think we should be able to see success.

In addition, the success of the project was framed in relation to the skills that participants would acquire as a result of participating in the project. The acquisition of skills and competencies relating to the production of the radio shows was seen as significant in defining the success of the project. For one participant, success meant that "everyone who is involved in the project is able to sufficiently use the equipment, to be able to confidently record their voices, which I think everyone is doing at the moment and you know, maybe ... the [radio studio] panel".

Other participants discussed successful outcomes in terms of the range of issues that will be covered in the radio shows:

I can just imagine very good things out of this project because we will cover a lot of issues in our society, internationally, continentally, globally; global issues that are not just Australian issues, but we will also touch other issues in other continents and I think that will be good success.

Depending on the ideas we are focusing on, for example, let me say I will be doing youth stuff, involving the youth in some of the ideas that I have. That means for me to say I have been successful, I should have included a lot of multicultural youth, youth from different backgrounds, and have them interviewed, have all sorts of information recorded ... then I can call it a success.

\section{Constructing success as making a difference}

The repertoire of success as making a difference was deployed on two levels: making a difference in the lives of the individual participants, and making a difference in the wider society. In line with the indicators for social inclusion identified by Long et al. (2002), the participants felt that the success of the project could be judged against its ability to foster increased personal development (including self-esteem and self-confidence, social skills, sense of achievement, empowerment and extending oneself in new directions); increased social cohesion (linked to social connections and notions of social capital) and making structures more open (for example, involvement in decision making, exercising rights and responsibilities and other forms of active citizenship). 
In relation to the second level, participants framed success in relation to the project's ability to effect change at the meso and macro level of society. For instance, the success of the radio program was seen as dependent on the following being achieved:

We really need to see some good results, really need to touch many lives, and people. We need to have more listeners; the increased numbers of listeners will actually make us feel good. I think that should actually happen. Our target should be having people to listen to our project, having people come and get interviewed by the interviewers of UniCast radio station. We should also have dignitaries from different offices come here telling us about issues of concern that we will be asking them.

Within this participant's narrative, the success of the radio program was closely linked with being able to address issues of concern that impact on the community and possibly influencing policy by bringing in 'dignitaries' into the conversations. It is also noteworthy that the quantitative discourse is also visible in the way in which success is framed in this narrative, as there is a concern for increased numbers of listeners to the program in order "to touch many lives". This definition of success offered by this participant is congruent with Grieco's (2005) view that social impact should be understood in terms of the project's ability to effect societal change.

Creating a social impact assessment tool based on participatory monitoring and evaluation processes

Long et al (2002) outline three levels by which the success of a project may be recorded milestones, outputs and outcomes, all of which are relevant to the P-HRS radio project. Milestones tend to indicate the attainment of specific stages throughout a project, often in conjunction with the staggered release of funding, as was the case with the P-HRS project and can be a sound way to gauge successful project management. Milestones for this project were simply reporting (by the Lead CI) to the funding body (the International Centre for Muslim and non-Muslim Understanding) on the progress of the project.

Outputs tend to be quantitative, for example the number of participants or audience members attending an event, and would include what is now referred to as Big Data (although not identified as such by Long et al in 2002). This level was articulated through the participants' construction "of success as making a difference", in relation to the project's ability to reach as 
wider audience as possible. Potential measurements of output for this project may be taken by counting social media interactions (for example likes, followers, shares, and comments on Facebook and Instagram), analysing statistics from the radio program's WordPress blog, and considering the number of community groups or individuals represented in the program content.

The third measurement, outcomes, provides opportunities for a nuanced understanding of the potential that action research projects have in advancing position of those who are socially excluded. It is this notion of outcomes that aligns most closely with social impact being measured in this project, and it is acknowledged that many outcomes are subjective, being measured either through self-evaluation or the close observation of others and/or are longitudinal in nature (Long et al 2002). The bottom-up and inside-out approach adopted for this study illuminates the different ways in which the notion of social impact can be understood at a micro level as subjectively defined and measured by participants.

Outcomes can be measured through all four of the aforementioned interpretative repertoires constructing success as participation, as collaborative and ongoing processes, as tangible outcomes, and as making a difference. From these repertoires, a set of key indicators has been developed to create a tool by which the social impact of this particular pilot project can be assessed, based on the participants' own negotiations of what constitutes its success. While not yet finalised, these indicators would ask participants to rate the following aspects:

- Personal and group participation in the project

- 'Happiness' about the participant's involvement in the project

- The collaborative process (teamwork) of the group during the project

- Satisfaction with the work produced by both the individual and the group

- Level of skills acquisition (including ability to use recording equipment, edit, conduct interviews and produce a radio program)

- The success of the radio series in covering issues that were important to the participant

- The success of the radio series in engaging (involving) community groups and other stakeholders from the community

- The project's positive influence on personal development (if any) 
It is expected that this measurement tool will involve a quantitative rating scale, along with the option to provide comment on their responses, in an attempt to collect additional thick data. Participants will be given the opportunity to respond either in written or spoken-word (recorded) format. This list of key indicators is valuable as it was elicited through a participatory monitoring and evaluation process that identifies the participants own indicators of success. It is important to note that the use of participants' subjective experiences as a marker of success runs in sharp contrast with current practices, which emphasise quantifiable performance indicators and outputs. The importance of such subjective experiences are not widely recognised within existing research yet it is at this level that participatory action projects are of relevance to participants.

\section{Conclusion}

Community broadcasting in Australia needs to be able to demonstrate its social impact in ways that are recognised and understood by funding bodies and stakeholder groups. This is no easy task, given the complexity of social impact measurement, and the diversity of the sector itself. Community broadcasting can be measured at a macro-level in terms of its impact on society as a whole, as well as through the micro-levels of the individual station, and, narrowing down even further, specific programs or projects. This research project focuses on the latter evaluation, and considers how to approach the social impact measurement of one particular pilot radio program produced by young people from refugee backgrounds living in Adelaide, South Australia.

It is important to recognise that any measurements of success of participatory action research projects should be developed in consultation with those involved in the project. To do otherwise would be in opposition to the spirit of participatory research methodology. This research recognises the recommendations of AMARC (2007) to employ participatory monitoring and evaluation processes. To achieve this, participants' discussions around measuring the success of the project, held in its first weeks, were analysed using discourse analysis to identify interpretative repertoires used by the participants to articulate notions of success. This analysis revealed the following interpretative repertoires:

1. Constructing success as participation

2. Constructing success as a (collaborative) process

3. Constructing success as tangible outcomes

4. Constructing success as making a difference 
These constructions of success were then developed into a set of key indicators that will be used at the completion of the radio series (and research project) to collect both quantitative and qualitative data. This information in combination with the documentation of outputs derived from social media usage (and other data as outlined above) will be used to measure the social impact of the project - as in the change created by activities as deemed important by those involved.

Grieco (2015) points out that developing a "one size fits all" impact measurement is problematic. While some attempts have been made to list the variables of social impact that could assist organisations to identify and assess, such standardised indicators potentially risk that organisations will rely on them instead of determining their own unique issues and potential impacts that need to be addresses and measured. In the spirit of participatory research, the bottom-up and inside-out approach outlined above validates the expertise of the participants' expertise by involving them in the evaluation process. This is useful for assessing the social impact of community radio projects that invest in participatory research methodology, as it enables all of those involved to produce social impact indicators that are people-centred and a genuine outcome of the research project itself. 
References

AMARC 2007, Community Radio Social Impact Assessment: Removing Barriers, Increasing Effetiveness. Challenges, Findings, Reflections, Experiences, Lines of Action for Community Radio stakeholders AMARC Montréal (Québec) Canada

Barraket, J and Yousefpour, N 2013, Evaluation and social impact measurement amongst small to medium social enterprises: process, purpose and value. Australian Journal of Public Administration 72(4): 447-458.

Barraket, J 2005, "Putting People in the Picture? The role of the arts in social inclusion", Social Policy Working Paper No. 4, Brotherhood of St Laurence, Fitzroy and Centre for Public Policy, Melbourne, https://minervaaccess.unimelb.edu.au/bitstream/handle/11343/34370/66889_00002321_01_barraket_arts_so cial_inclusion_1.pdf?sequence $=1$, accessed $30^{\text {th }}$ September 2015

Bloch, B 2012, Everyone's Story Counts" Measuring Social Impact in the Not-for Profit Sector - an Overview, Cosmoplitan Civil Societies Journal, Vol.4, No.3, https://epress.lib.uts.edu.au/journals/index.php/mcs/article/view/2623, accessed $6^{\text {th }}$ October 2015

CBAA 2015, Community Radio and the 2015-16 Federal Budget, https://www.cbaa.org.au/article/community-radio-and-2015-16-federal-budget, accessed $8^{\text {th }}$ October 2015.

CBF 2015, About Australian Community Broadcasting http://www.cbf.com.au/sector/aboutaustralian-community-broadcasting, accessed $8^{\text {th }}$ October 2015.

Every, D. \& Augoustinos, M. 2007. Constructions of racism in the Australian parliamentary debates on asylum seekers. Discourse and Society, 18, 411-436

Edley, N. 2001. Analysing masculinity: Interpretative repertoires, ideological dilemmas and subject positions In: Wetherell L, M., Taylor, S. \& Yates, S. J. (eds.) Discourse as data. A guide for analysts. London: Sage

Gough, D 2014 Community radio 'will die a slow death' if audit cuts adopted, May 7 http://www.smh.com.au/entertainment/tv-and-radio/community-radio-will-die-a-slow-deathif-audit-cuts-adopted-20140510-zr6et.html, accessed $8^{\text {th }}$ October 2015. 
Grieco, C 2015, Assessing Social Impact of Social Enterprises, SpringerBriefs in Business, http://link.springer.com/book/10.1007\%2F978-3-319-15314-8, accessed 6 ${ }^{\text {th }}$ October 2015.

Hearn, G, Tacchi, Jo, Foth, Marcus and Lennie, June 2009, Action Research and New Media, Hampton Press, New Jersey.

Jallov, B 2005, “Assessing community change: development of a 'bare foot' impact assessment methodology", The Jadio Journal - International Studies in Broadcast and Ausio Meida, Volume 3, Number 1, pp.21-34.

Kramer, M., Parkhurst, M. \& Vaidyanathan, L. 2009, Breakthroughs in Shared Measurement and Social Impact, FSG Social Impact Advisors,

http://www.fsg.org/publications/breakthroughs-shared-measurement, accessed $29^{\text {th }}$ September 2015

Larkin, R. 2013, Using Outcomes to Measure Nonprofit Success, Nonprofit Quarterly, https://nonprofitquarterly.org/2013/07/02/using-outcomes-to-measure-nonprofit-success/, accessed 25/10/15

Long J, Welch, M, Bramham, P, Butterfield, J, Hyleton, K \& Lloyd, E 2002, "Count me in: the dimensions of social inclusion through culture, media \& sport", Department of Culture, Media \& Sport, Leeds Metropolitan University, Leeds.

Mass, K and Liket K 2011, Social impact measurement: Classification of methods. In Burritt, R, Schaltegger, S, Bennet, M, Pohjola, T, Csutora M (Eds.) Environment management accounting and supply chain management, Eco-efficiency in industry and science, Volume 27, Springer, Netherlands

Maughan C. 2012. Monitoring and evaluating social impacts in Australia. CRC-REP Working Paper, CW003. Ninti One Limited, Alice Springs.

National Commission of Audit 2014, Towards Responsible Government, Appendix to the Report of the National Commission of Audit, Volume 2, http://www.ncoa.gov.au/report/docs/appendix_volume\%202.pdf, accessed $8^{\text {th }}$ October 2015 NEMBC, 2011, Engaging Communities: Involving Emerging and Refugee Communities at your Radio Station, 
http://www.nembc.org.au/userfiles/file/4.Projects/1.\%20Media\%20Kit/Engaging\%20Commu nities\%20Web.pdf, accessd 25/10/15

Notley, T., Lowenthal, A., Gregory, S. (2015). 'Video for Change: Creating and Measuring Social Impact.' A Working Paper by the Video4Change Network, https://wwwv4c.org/en/impact_working_paper, accessed $29^{\text {th }}$ September 2015

Order, S 2012 Community radio and the notion of value: a divergent and contested theoretical terrain, paper presented at the Cultural Studies Association of Australasia Conference: Cultural ReOrientations and Comparative Colonialities”, Adelaide, 22-24 November 2011, http://www.unisa.edu.au/Documents/EASS/MnM/csaa-proceedings/Order.pdf accessed 25/10/15.

Order, S 2013, “The Altruism of Community Radio?”, Asia Pacific Media Educator, 23(2), pp.381-401.

Patton, R 2003, Managing and measuring social enterprises, Sage, London.

Productivity Commission 2010, Contribution of the Not-for-Profit Sector, Canberra, http://www.pc.gov.au/inquiries/completed/not-for-profit/report/not-for-profit-report.pdf, accessed $6^{\text {th }}$ October 2015

Wang, T. (2013) Big Data Needs Thick Data. Ethnography Matters.

http://ethnographymatters.net/blog/2013/05/13/big-data-needs-thick-data/, accessed $30^{\text {th }}$ September 2015

Wetherell, M. 2015. Discursive psychology: key tenents, some splits, and two examples. In: Parker, I. (ed.) Handbook of critical psychology. Hove, Routledge.

Wetherell, M., Taylor, S. \& Yates, S. J. 2001. Discourse theory and practice: a reader, Sage. Whiteman, D. 2004, "Out of the theaters and into the streets: A coalition model of the political impact of documentary film and media", Political Communications, vol 21, no. 1, pp.51-70.

Zappala, G \& Lyons, M 2009, Recent approaches to measuring social impact in the Third sector: An overview, CSI Background Paper, No. 6, The Centre for Social Impact, Melbourne, 
http://www.socialauditnetwork.org.uk/files/8913/2938/6375/CSI_Background_Paper_No_5__Approaches to measuring_social_impact_-_150210.pdf, accessed $6^{\text {th }}$ October 2015. 